\title{
Finite element analysis on seismic performance of EWECS composite column
}

\author{
Fauzan $^{1, *}$, Ruddy Kurniawan ${ }^{1}$, and Zev Al Jauhari ${ }^{1,2}$ \\ ${ }^{1}$ Department of Civil Engineering, Andalas University, 25163 Padang, Indonesia \\ ${ }^{2}$ Department of Civil Engineering, Padang Institute of Technology, 25143 Padang, Indonesia
}

\begin{abstract}
A new hybrid Engineering Wood Encased Concrete-Steel (EWECS) structural system is developed in Japan to solve the limitation of story number for wooden structure. In this structural system, the EWECS column consist of concrete encased steel (CES) core and wood panel as a column cover. An experimental study has been done to investigate the seismic performance of the EWECS column, which is compared with CES column without concrete cover. The main parameter is the presence of wood panel. In order to validate the experimental results, a 3D finite element (FE) model is built by using ANSYS APDL v.14. The FE results indicate that FE EWECS column model has excellent performance, which has a stable spindle-shape hysteresis loops. The presence of wood panel contributes to improve the maximum flexural capacity of the EWECS column about $13 \%$. In addition, the stress distribution on the FE models has good correlation with failure mode of the EWECS column specimens. Generally, the numerical results are able to accurately simulate the seismic behaviour of the EWECS column on test results.
\end{abstract}

\section{Introduction}

It has been known that steel reinforced concrete (SRC) structures are typical composite structural systems which have excellent earthquake resistance with high capacities and deformability. However, some disadvantages are found in SRC structures, especially in difficulty to construct both steel section and reinforced concrete. Concrete encased steel (CES) structure consisting of only steel section and concrete is proposed by Kuramoto to overcome these problems [1]. Some experimental studies have been carried out on CES columns subjected to both axial and cyclic loads. The results showed that the CES columns have excellent seismic behaviour.

Based on the SRC and CES ideologies, a new hybrid engineering wood encased concrete-steel (EWECS) structural system is developed for low to high seismic zones. This new composite structural system overcomes the limitation of the number of stories for wooden structures. In this structural system, the EWECS column consist of concrete encased steel (CES) core and wood panel as a column cover. Both economical and structural benefits are realized due to the use of wood panel as column cover. The wood panel acts directly as forming for the composite column during construction, decrease the

\footnotetext{
${ }^{*}$ Corresponding author: fauzan@ft.unand.ac.id
} 
labor and materials needed, and consequently reduce the construction cost. From the structural point of view, the wood panel contribute to provide core confinement and resistance to bending moment, shear force, and column buckling $[2,3]$.

An experimental study on the performance of EWECS composite columns subjected to both constant axial and cyclic loads has been done by one of the authors [2] with the main parameter is the presence of wood panel. In this experimental study, the EWECS column is compared with the CES column without concrete cover (the core of EWECS column) in order to investigate the seismic behaviour of EWECS column and the contribution of wood panel on the EWECS column. The performance of both columns is evaluated in terms of hysteresis loops and failure modes.

In order to validate the experimental results, a tridimensional finite element model by using ANSYS APDL v14.0 [4] is developed. This software is a comprehensive generalpurpose finite element computer program that contains over 100000 lines of code that very powerful and impressive to be used to solve a variety of problems [5]. ANSYS is capable of performing static analysis that suitable for the current task. The developed model takes into consideration the nonlinear behaviour of material.

\section{The geometry of 3D finite element models}

All the specimens have a column with $1600 \mathrm{~mm}$ height. The column section of EWECS column is $400 \mathrm{~mm}^{2}$, while that of CES core is $300 \mathrm{~mm}^{2}$. The EWECS column is covered by a wood panel with a thickness of $45 \mathrm{~mm}$, while its core section is same as that of CES core column, as shown in Fig. 1. Steel encased in each column has a cross section combining two H-section steels of 300x150x6.5x9 mm.
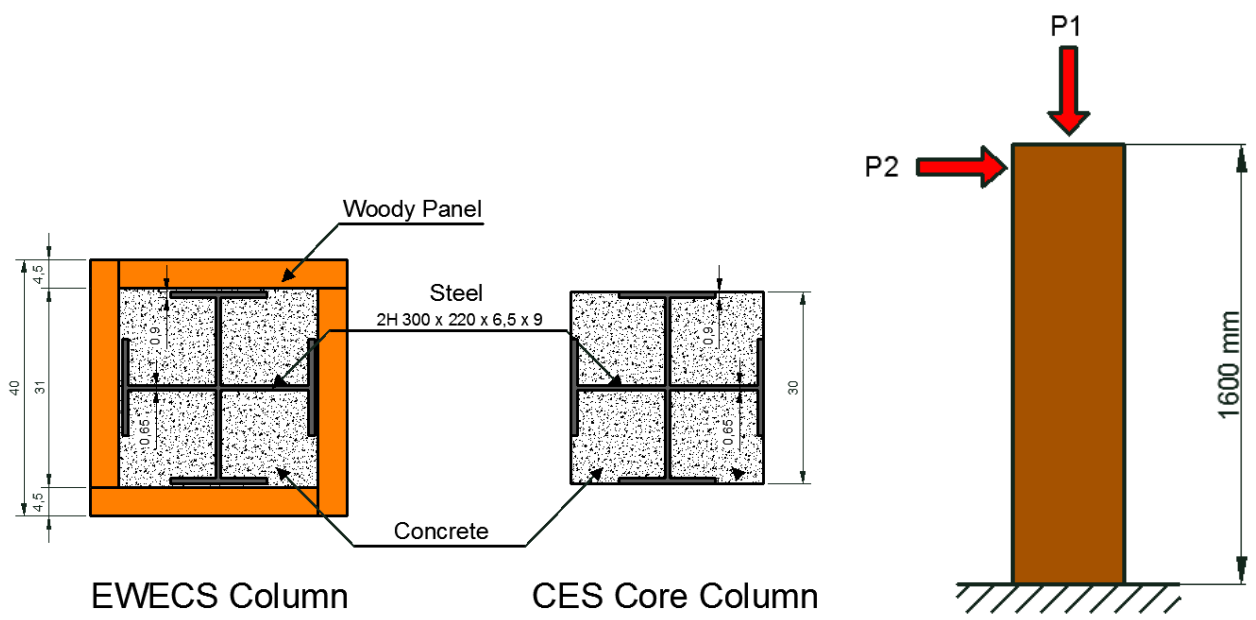

EWECS Column

CES Core Column

Fig. 1. Details of test specimen of CES core and EWECS composite columns (P1 = axial constant load, P2 = lateral cyclic load)

The FE models are developed to accurately represent the geometrical configuration and dimensions of the test specimens. The CES core and EWECS composite columns are modelled as illustrated in Fig. 2. The concrete, steel, and wood panels are modelled as block and solid cube with an equivalent length representing the total area of specimens. 


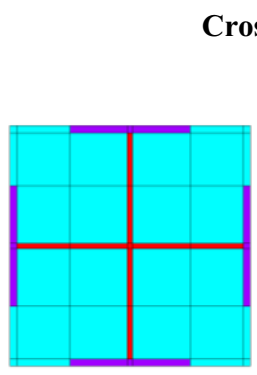

CES Core

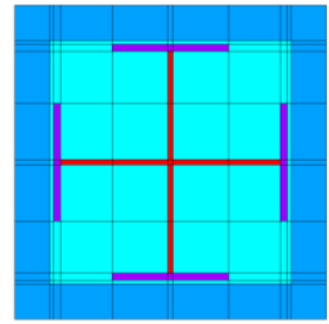

EWECS

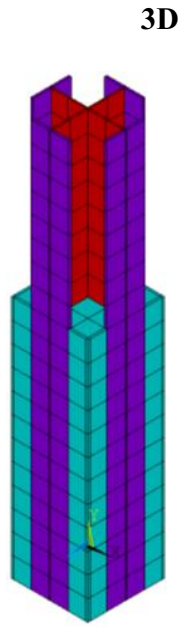

CES Core

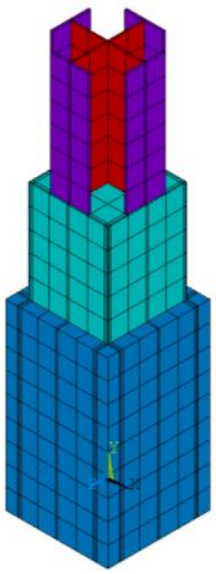

EWECS

Fig. 2. The FE model of CES core and EWECS composite column models

\section{Types of element}

Two types of elements are used in the modeling of steel H-section, concrete, and wood panel. ANSYS solid element, SOLID185, is used to modeling steel section and wood panel, while SOLID65 is used to modeling concrete of the EWECS column. The SOLID185 and SOLID65 elements are a 3D hexahedral element defined by eight nodes as shown in Fig. 3. These elements have three translational degrees of freedom at each node in the nodal $\mathrm{x}, \mathrm{y}$, and $\mathrm{z}$ directions. The SOLID185 element has capability of plastic deformation, hyper elasticity, stress stiffening, creep, large deflection, and large strain. The most important aspect of SOLID65 element is the treatment of nonlinear material properties. The element has the capability of plastic deformation, creep, cracking in three orthogonal directions, and crushing in compression [4].

The FE model in this study is considered perfectly-bonded for material interface between steel and concrete [6], while the unbonded for material interface between wood and concrete that performed by slightly reducing the constitutive model of the materials. This assumption is applied because bonded and unbonded between adjacent materials (wood and concrete) do not much influence for flexural capacities of the columns in the experimental results (the comparison of seismic behaviour between EWECS Column with and without shear studs) [7].
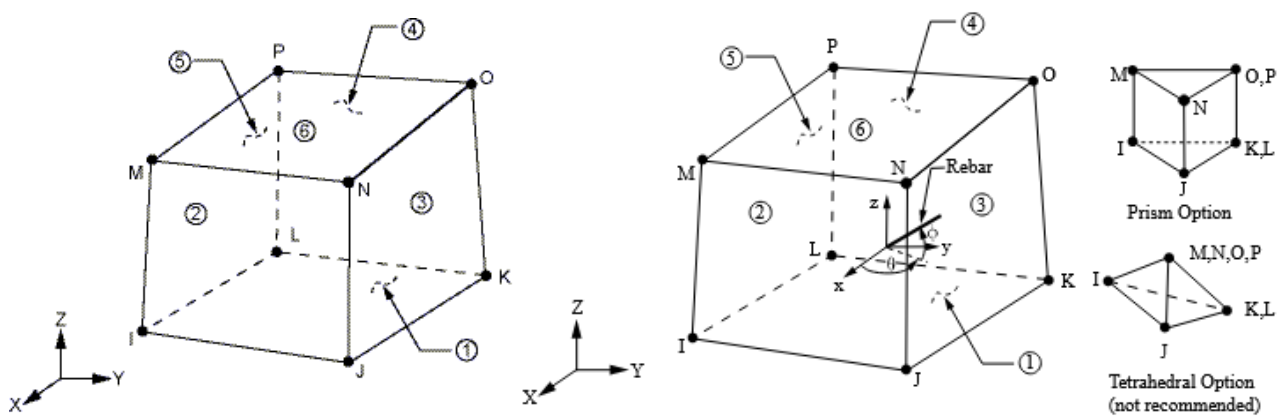

Tetrahedral Option (not recommended)

Fig. 3. Solid185 and Solid65 ANSYS Element [4] 


\section{Material properties, meshing, boundary conditions, and loads}

\subsection{Material properties}

\subsubsection{Concrete}

The compressive strength of concrete used in both specimens is $35 \mathrm{MPa}$. A peak concrete strain 0.0025 is used in the analysis. Fig. 4(a) presents the tensile stress-strain curve used for the concrete. The stress-strain relationship in the rising region is designed on the model developed by Saenz [8], which is built in the program. The tensile relaxation (softening) is presented by a sudden reduction of the tensile strength to $0.6 f_{\mathrm{r}}$ upon reaching the tensile cracking strain $\varepsilon_{\mathrm{cr}}$. After this point, the tensile response decreases linearly to zero stress at a strain $6 \varepsilon_{\text {cr }}$ as shown in Fig. 4(b).

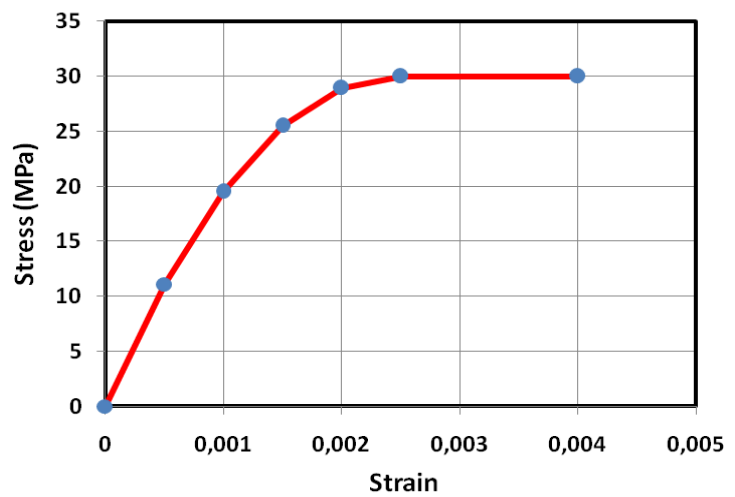

(a)

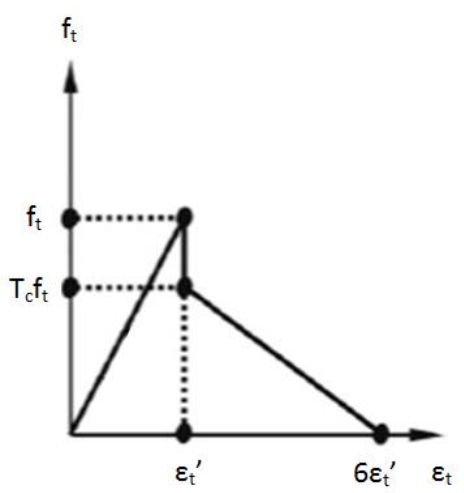

(b)

Fig. 4. Idealized (a) compression and (b) tensile stress-strain curve for concrete

Additional concrete material data, such as the shear transfer coefficient $\beta_{\mathrm{t}}$ for open cracks and $\beta_{\mathrm{c}}$ for closed cracks are also needed for the concrete constitutive material data table. The shear transfer coefficients $\beta_{\mathrm{t}}$ and $\beta_{\mathrm{c}}$ control the amount of shear transfer across the cracks. Typical shear transfer coefficients range from 0.0 to 1.0 , with 0.0 represents a smooth crack (complete loss of shear transfer) and 1.0 represents a rough crack (no loss of shear transfer). A shear transfer model developed by Al-Mahaidi [9] is included in the analysis, with value 0.75 and 0.9 is used in the FE model for $\beta_{\mathrm{t}}$ and $\beta_{\mathrm{c}}$, respectively. The fracture criterion of concrete is applied by adopting the five parameter model of WilliamWarnke [10].

\subsubsection{Steel}

The yield strength of steel used in each models are 412.5 and $453 \mathrm{MPa}$ for flange and web steel, respectively. The constitutive model of the steel used in this study is a perfectly elastic-plastic criterion [11]. At first, this curve is elastic, then it is assumed to be perfectly plastic (bilinear isotropic model), as shown in Fig. 5(a). This curve is suitable for representing stress-strain characteristics of normal and high quality steel section. Poisson's ratio is assumed 0.3 for this study. 


\subsubsection{Wood Panel}

The compressive strength and modulus elasticity of wood are $36.5 \mathrm{MPa}$ and $10500 \mathrm{MPa}$, respectively. For the design allow the force to be applied in the direction parallel to the annual growth ring of the wood, some existing concrete models built in the program by many researchers might be used in the analysis with some modifications [12]. Stress-strain relationship is modeled by linearly increasing model with slightly reduction (5\%), as shown in Fig. 5(b). The fracture criterion of wood is adopted by following the rule of the five parameter model of William-Warnke [10] for concrete with the input of wood material characteristic. The maximum tensile strength of the wood panel during the analysis is taken as $5 \mathrm{MPa}$. This value is taken into consideration the lower tensile strength in the direction perpendicular to the grain. To account for shear stiffness reduction by shear crack deformation, the shear transfer model for concrete developed by Al-Mahaidi [9] is included by using modified shear transfer coefficient $\beta_{\mathrm{c}} 0.35$ for wood.

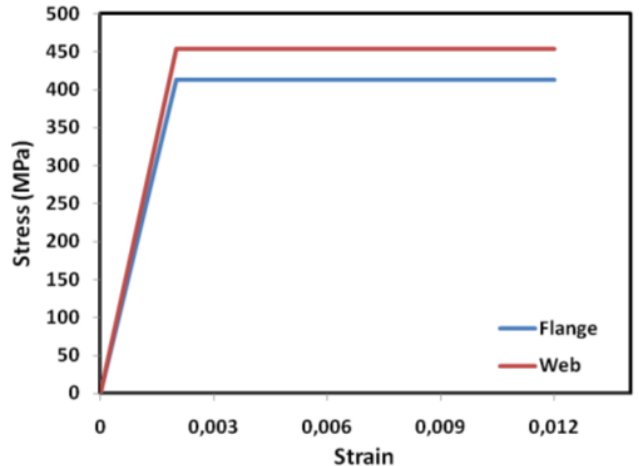

(a)

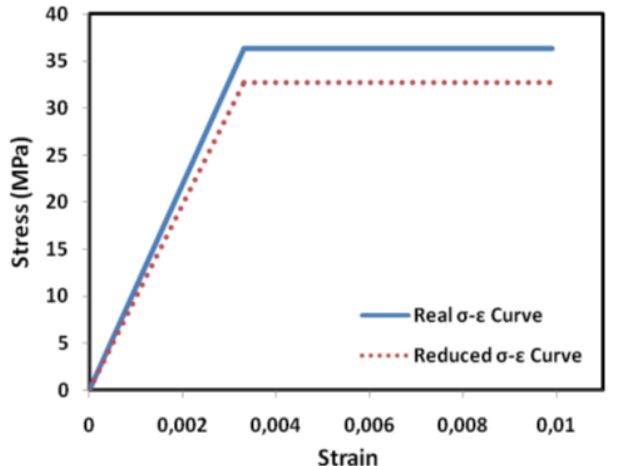

(b)

Fig. 5. Tensile stress-strain curves for (a) steel and (b) wood panel

\subsection{Meshing}

The mesh density is chosen so that the elements aspect ratio is nearly equal to one. This provided adequate accuracy and fair computational time in modelling the composite columns. The total numbers of element used are 3995 and 5095 elements for CES core and EWECS, respectively. This is an adequate refinement for the constructed the $3 \mathrm{D} \mathrm{FE}$ models.

\subsection{Boundary Conditions}

In the FE models, the boundary conditions are as follows: An anchor plate/ stub $(700.700 .400 \mathrm{~mm})$ is used in the model at the top and bottom of the column. Fixed at the bottom of the column and roller supported at the top of the column as shown in Fig. 6(a). Nodes at the bottom of the column are restrained in all translational degrees of freedom, and the top of the column is restrained in the vertical y direction. The lateral y direction is restrained since the column prevent any displacement in this direction. The nodes at the two edge lines of the column are coupled in the vertical y direction to ensure all the nodes associated with this line move together. The nodes located at the middle face of the column along the direction of the applied displacement are coupled in the horizontal $\mathrm{x}$ direction. It should be noted that the boundary conditions are the same for all loading cycles. 


\subsection{Loads}

The loading is applied in the model as follows:

- Constant axial load, approximately $770 \mathrm{kN}$ are applied to the top face columns. This is represented in the FE model by applying a point pressure $1.1 \mathrm{kN}$ on the upper elements (steel plate) of a total nodal area 717.

- The lateral loading history for the model is based on story drift and is the one recommended for use in the experimental program [3]. This is represented in the finite element model by applying the displacement in cycles of loading and unloading at the top edge of the column. The incremental loading cycles are controlled by story drift, $\mathrm{R}$. The lateral load sequence consists of one cycle to each story drift, R $0.5,1,1.5,2,3$ and 4\% followed by half cycle to R 5\%, as shown in Fig. 6(b). It should be noted that the story drift is equal to the applied lateral displacement at the top of the column face divided by the height of column.

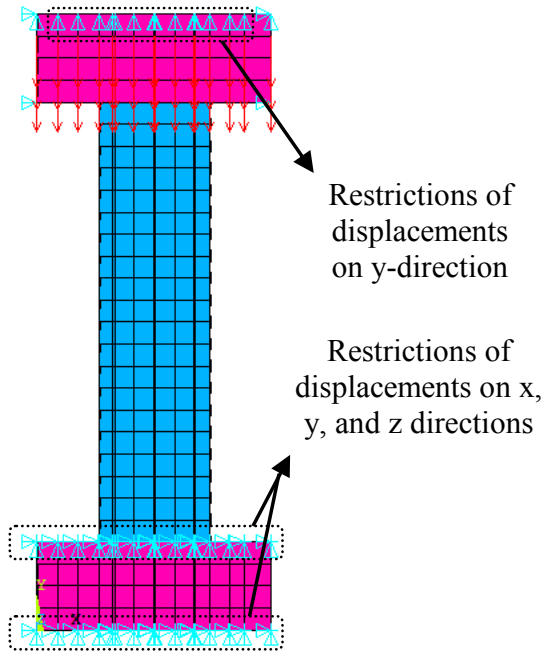

(a)

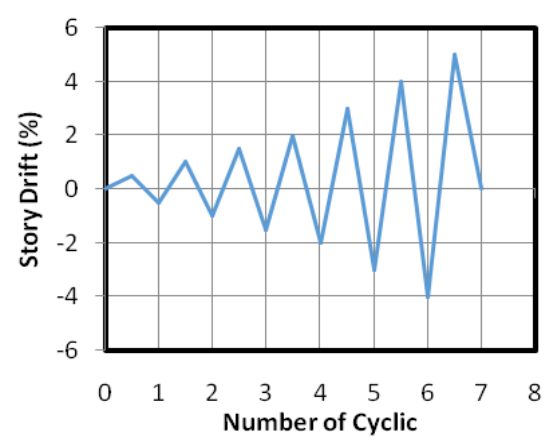

(b)

Fig. 6. (a) Boundary conditions, (b) Lateral cyclic load applied in the FE model

The applied cyclic displacements are divided into a series of increments called load steps and load substeps. At the end of each incremental solution, the program adjusts the stiffness matrix of the model before proceeding to the next incremental load step in order to reflect the nonlinear changes in the model's structural stiffness. To predict and control load step size increments, the automatic time stepping option is turned on in this study. The model stiffness is updated in ANSYS by Newton-Raphson equilibrium iterations [13].

\section{Result and discussions}

\subsection{Hysteresis Characteristics}

The experimental lateral load-displacement (hysteresis) loops for the CES core and EWECS columns are compared with those obtained from the FE analysis for the entire loading history as shown in Fig. 7. The figure shows that the analytical results for story shear versus story drift of the specimens showed a good agreement with the test results. Both the specimens and models showed ductile and stable spindle-shaped hysteresis loops. 


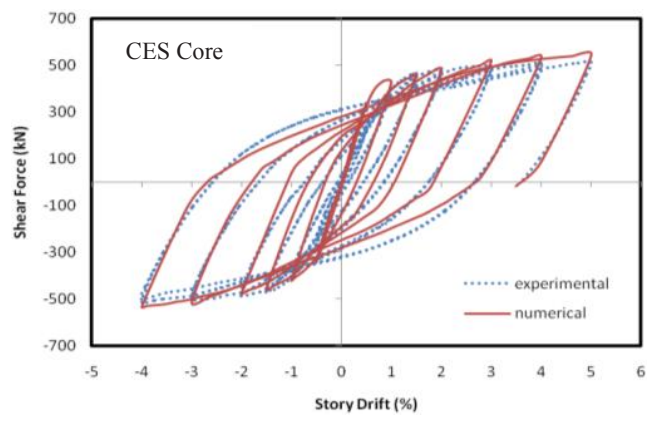

(a)

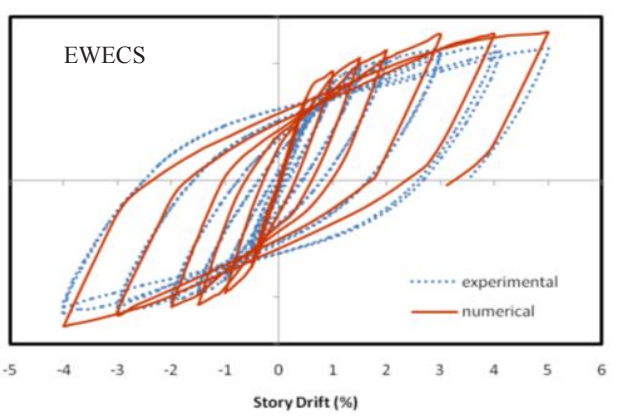

(b)

Fig. 7. Comparison between numerical and experimental result of story shear and story drift response of (a) CES and (b) EWECS composite columns

From the FE model, the maximum lateral shear force for CES core column is $541 \mathrm{kN}$ obtained at $\mathrm{R} 5 \%$. This is approximately 5.4\% higher than the results obtained from the experimental $(513 \mathrm{kN})$. It is clear from Fig. 7(a) that the FE and experimental results are almost the same in each stage of cyclic loading. The different percentage of lateral shear force in each stage of loading cycles between the FE analysis and the experimental results is around 5.5\%. The maximum shear force for EWECS column is $628 \mathrm{kN}$ at R 5\% from the FE analysis, which is $9.1 \%$ higher than the experimentally obtained data $(573 \mathrm{kN})$ at $\mathrm{R} 4 \%$. The FE model behaved less dissipated energy in the last stages of loading cycles than the experimental tested, as seen in Fig. 7(b). The different percentage of lateral shear force in each stage of loading cycles between the FE analysis and the experimental results is around $8.4 \%$. The difference between the FE and experimental results can be attributed to mesh refinement, idealized boundary conditions, material nonlinearity, and the specified coefficient of friction between contact surfaces at the material interface of the column.

\subsection{Failure modes}

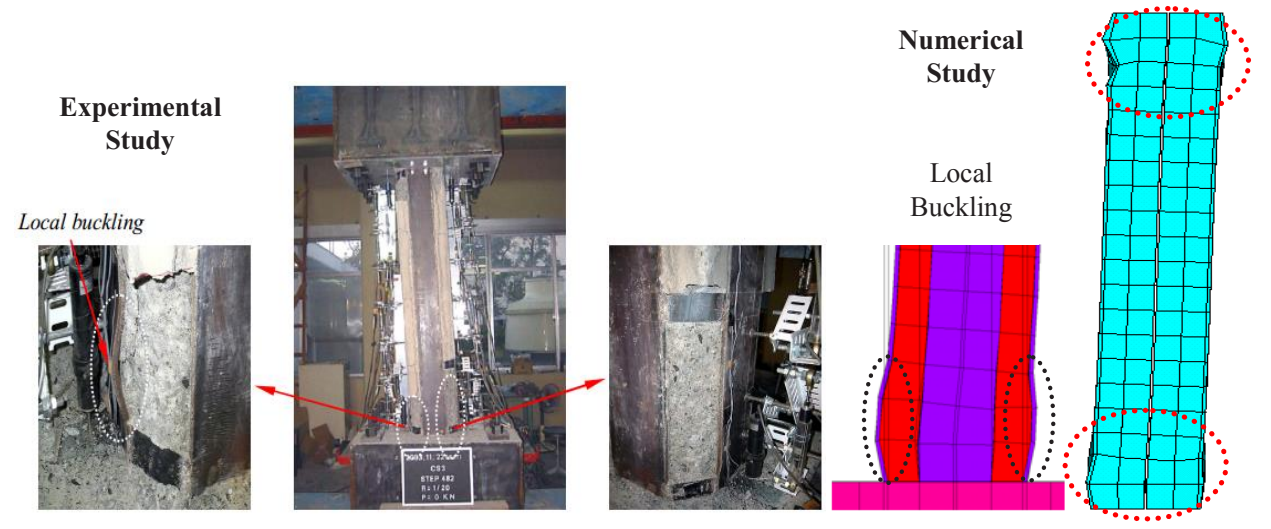

Fig. 8. Comparison of failure patterns on CES core column at R 5\% between experimental and numerical studies

Both in the experimental specimen and FE model, flexural cracks in the concrete of CES core appeared to both top and bottom of the column at R $0.5 \%$. Subsequently, the cracks extended at the corners of the column with an increase of the story drift. The crushing of the concrete is found at the corners of both top and bottom parts of the column, and the 
buckling of the steel flange is observed at the west side in the bottom part of the column, as shown in Fig. 8.

Up to a story drift, R 3\%, no damage is observed at the EWECS specimen faces. The wood panel buckled outward, and finally the cracks in the wood panel occurred at the corners of the column at R 5\%. Extracting the wood panel after testing, it is observed that the in-filled concrete had crushed in flexure at both top and bottom of the column, and there is no local buckling occurred at the encased steel. This failure mechanism is also observed in the FE model, as seen in the Fig. 9.
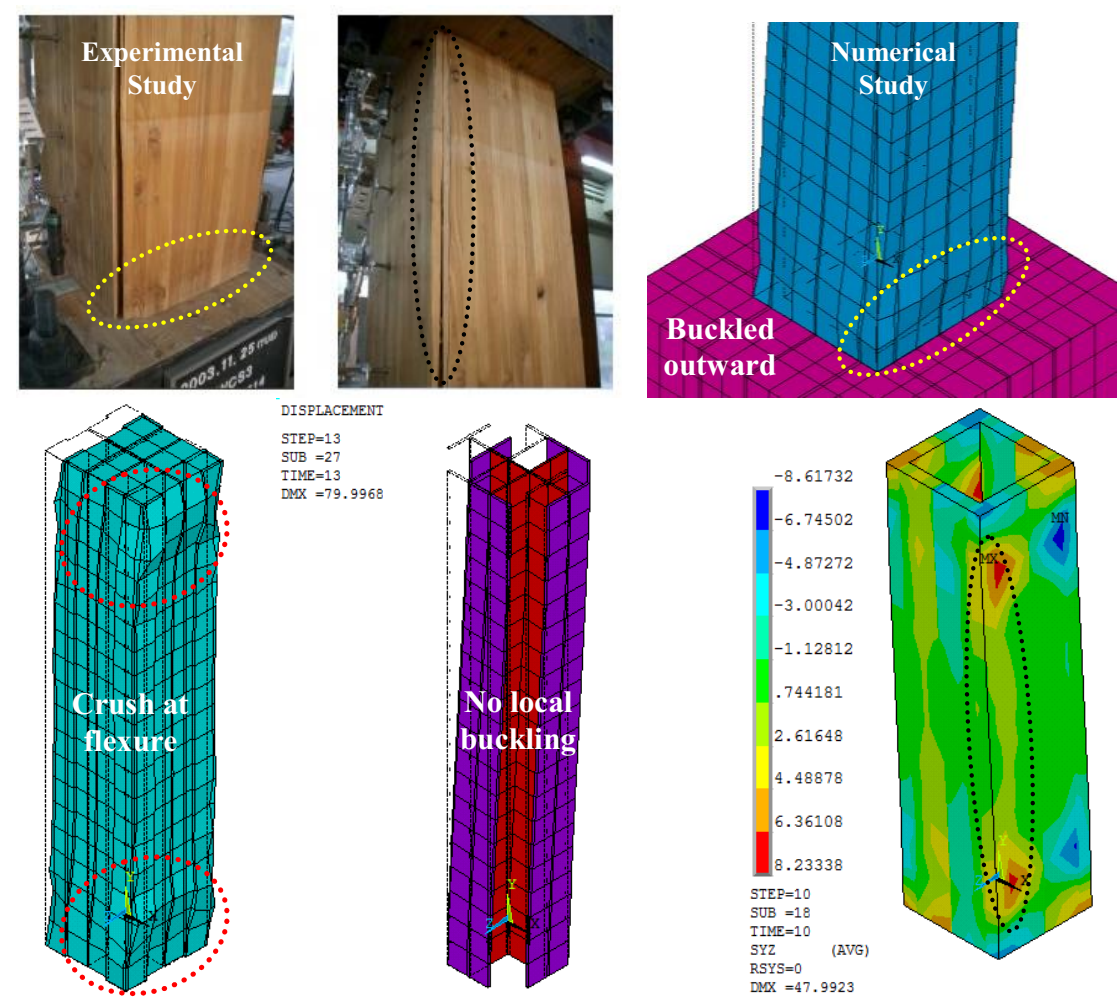

Fig. 9. Comparison of failure patterns on EWECS column at R of $5 \%$ between experimental and numerical studies

\subsection{Principal Stress Distribution}

The stress and strain in the material element are also analysed to validate the FE models. A principal strain 0.002 is reachead in the encased steel of CES and EWECS models at story drift $0.51 \%$ and $0.55 \%$, respectively, as indicated that the steel has first yield in red in Fig. 10. The first yield in the corner region both top and bottom of the steel during experimental specimens are at $\mathrm{R} 0.88 \%$ and $0.76 \%$, respectively. These results indicated that the FE model satisfactory portrayed the behaviour of the columns.

Both CES and EWECS models, first crack in the concrete occurs at the story drift $0.4 \%$ and $0.55 \%$ in the field zone of FE model, indicated by maximum principal stress (tensile) is greater than the tensile strength of concrete $(1.8 \mathrm{MPa})$ as shown inside the oval shape in Fig. 11. These cracks spread on the strut area along the horizontal direction. The principal shear stress in the wood panel of the FE model inside the oval shape in the Fig. 9 shows that cracks occurred on the panel at a shear stress of approximately $8 \mathrm{MPa}$ (maximum shear 
force) in the location where the panel is assembled together by using wood glue. The tangential shear strength of the normal wood suggested by Calderoni [14] is average 7.44 $\mathrm{MPa}$. The crack occurring at this location might be attributable to the weak shear strength of the connection using wood glue during construction of the specimens. Cracks also formed at the opposite side of the column, and propagated along the column height.
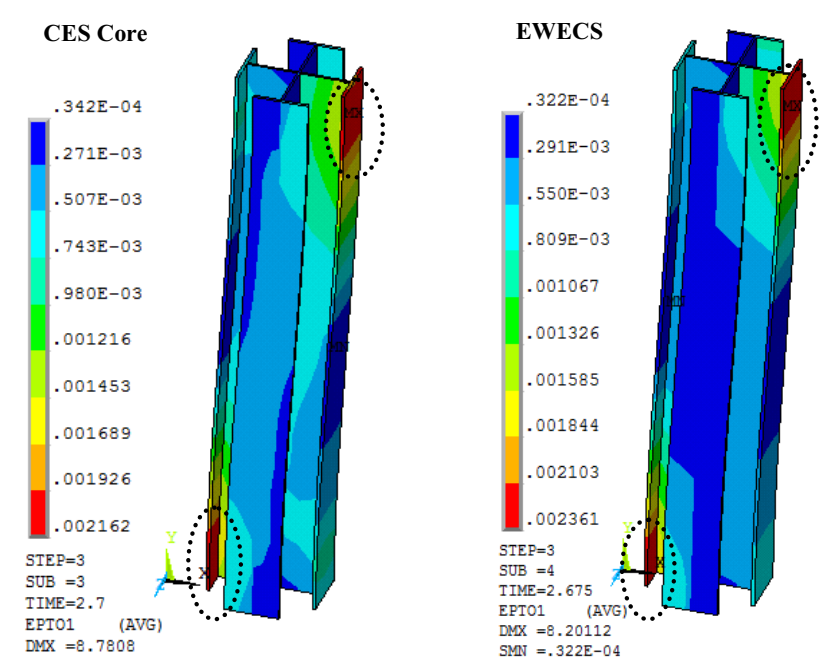

Fig. 10. Principal strain in the encased steel of CES core and EWECS columns at first yielding
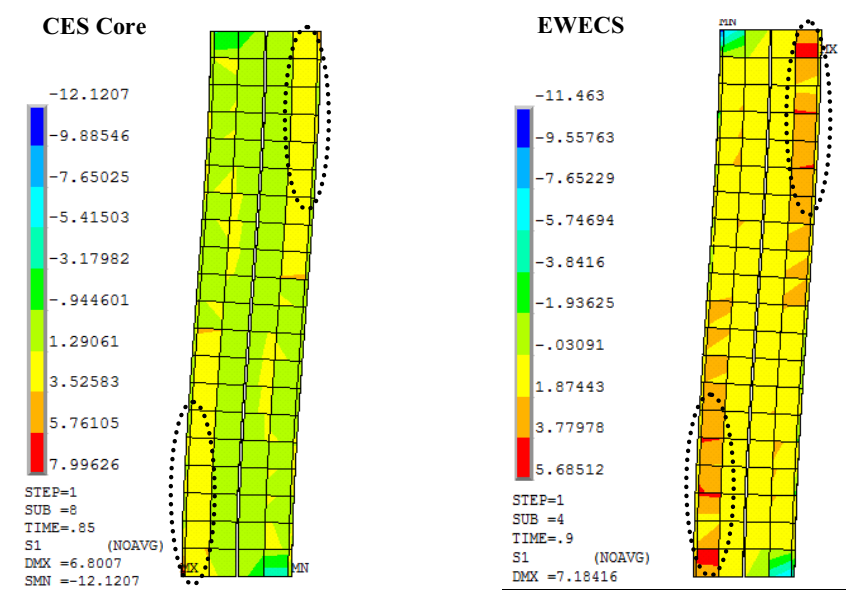

Fig. 11. Principal stress in the concrete of CES core and EWECS columns at first crack

\section{Conclusions}

Based on the study presented here, the following conclusions can be drawn:

1. The hysteresis loops from the FE analysis have a stable spindle-shape, which correlated fairly well with experimental results. Good correlation exists in all stages of cycling loading. The different percentage of lateral shear force in each stage of 
loading cycles between the FEA and the experimental results are around $8.4 \%$ and $5.5 \%$ for EWECS and CES core columns, respectively.

2. FE analysis results show that the wood panel contributes to flexural capacity of EWECS column until large story drift, R 5\%, although the cracks in the wood occured after R 3\%. The wood panel contributes to improve the maximum flexural capacity about $13 \%$.

3. The stress distribution on the FE models well represents the failure mode of the CES core and EWECS column specimens.

4. Generally, the numerical results are able to accurately simulate the seismic behaviour of the EWECS composite columns on experimental study.

\section{References}

1. H. Kuramoto, H. Takahashi, M. Maeda, Feasibility study on structural performance of concrete encased steel columns using high performance fiber reinforced cementitious composites, Summaries of Technical Papers of Annual Meeting, Architectural International of Japan (AIJ), C-1 pp. 1085-1088 (2000)

2. Fauzan, H. Kuramoto, Y. Shibayama, T. Yamamoto, Structural behaviour of engineering wood encased concrete-steel composite columns, Proc. of the Japan Concrete Institute (JCI), 26(2) pp. 295-300 (2004)

3. H. Kuramoto, Fauzan, Feasibility study on engineering wood encased concrete-steel composite columns, Proc. 11th Int. Colloquium on Structural and Geotechnical Engineering (11thICSGE), Ain Shams Univ., Cairo, Egypt (2005)

4. ANSYS Version 14, User's and Theory Reference Manual, (2010)

5. S. Moaveni, Finite element analysis: theory and application with ANSYS, Minnesota State University, Mankato, (1999)

6. A. Leskes, S. Grambicka, Theoretical and experimental studies on composite steelconcrete columns, Concrete and Concrete Structures 2013 Conference, Proc. Engineering 65 Sciencedirect, pp. 405-410 (2013)

7. Fauzan, H. Kuramoto, Seismic performance of EWECS composite columns in new hybrid structural system, Composite Construction in Steel and Concrete VI, pp. 263$275(2011)$

8. L. P. Saenz, Discussion of equation for the stress-strain curve of concrete, J. American Conc. Inst. (ACI), 61(9) pp. 1229-1235 (1964)

9. R. S. H. Al-Mahaidi, Nonlinear finite element analysis of reinforced concrete deep members, 79(1), Dept. of Structural Engineering, Cornell Univ., NY (1979)

10. K. L. William, E. P. Warnke, Constitutive model for the triaxial behavior of concrete, Proc. Int. Association for Bridge and Structural Engineering IABSE 19, Zurich, Switzerland, (1975)

11. J.B.M. Sousa, Caldas R.B., Numerical analysis of composite steel-concrete columns of arbitrary cross section, J. Struct. Eng. ASCE 131(11) pp. 1721-1730 (2005)

12. H. Kuramoto, B. Li, K. Meas, Fauzan, Experimental and analytical performance evaluation of engineering wood encased concrete-steel beam-column joints, J. Struct. Eng. ASCE 137(8) pp. 822-833 (2011)

13. R.A. Hawileh, Nonlinear finite element analysis and modeling of a precast hybrid beam-column connection subjected to cyclic loads, J. Appl. Math. Model. Sciencedirect 34 pp. 2562-2583 (2010)

14. C. Calderoni, G. D. Matteis, C. Giubileo, F. M. Mazolani, Flexural and shear behavior of ancient wood beams: experimental and theoretical evaluation, J. Struct. Eng. 28(5) pp. 729-744 (2006) 